\title{
Delitos imprudentes en el marco de las actividades empresariales. Una observación desde la cultura de la prevención
}

\author{
Reckless Crimes in the Context of Business \\ Activities: An Observation from the Culture \\ of Prevention
} Delitos imprudentes no âmbito das
atividades empresariais. Observações a
partir da cultura da prevenção

Roberto Cruz Palmera* * https://orcid.org/0000-0003-4236-1261. Universidad Autónoma del Caribe, Colombia.
roberto.cruz56@uac.edu.co 


\section{Resumen}

La inclusión de los delitos imprudentes de cara a la responsabilidad penal de las personas jurídicas ha sido tratada escasamente por la doctrina. Esto, debido a que otros temas, como la culpabilidad, absorben la discusión en esa materia y dejan de lado algunos asuntos por tratar, como la sanción de los tipos imprudentes. En esta contribución expongo algunas razones por las cuales sancionamos acciones imprudentes cometidas en el marco de las actividades empresariales. Dicho de otra manera, pongo de manifiesto algunos motivos por los cuales se puede ver justificado el castigo de esta clase de conductas.

\section{Palabras clave}

Actividades empresariales; delitos; dolo; imprudencia; responsabilidad penal. 


\section{Abstract}

The inclusion of reckless crimes in the criminal liability of legal persons has been poorly treated by doctrine because other issues, such as guilt, have absorbed the discussion, leaving aside important matters such as the penalization of reckless actions. This paper expounds why reckless crimes committed in the context of business activities are penalized. In other words, it highlights some reasons that justify the punishment of this kind of behavior.

\section{Keywords}

Business activities; crimes; criminal liability; fraud; negligence. 


\section{Resumo}

A doutrina tem tratado de forma escassa a inclusão dos delitos imprudentes ante a responsabilidade penal das pessoas jurídicas. Isso devido a que outros temas, como a culpabilidade, absorvem a discussão nessa matéria e deixam de lado alguns assuntos como a punição dos tipos imprudentes. Nesta contribuição, exponho algumas razões pelas quais sancionamos ações imprudentes cometidas no âmbito das atividades empresariais. Em outras palavras, manifesto alguns motivos pelos quais a sanção desse tipo de comportamento pode ser justificada.

\section{Palavras-chave}

Atividades empresariais; delitos; dolo; imprudência; responsabilidade penal. 
Sumario: Introducción. 1. Breve análisis de los delitos previstos por el legislador: criterios de clasificación. 1.1. Por el bien jurídico. 1.2. Por la gravedad de la conducta. 1.3. Por la clase de delitos. 2. El castigo de acciones imprudentes al interior de la empresa. 3. Conclusión. Bibliografía

\section{Introducción}

1. En estas páginas explico por qué las personas jurídicas responden por delitos imprudentes. Adelanto que no se trata de una descripción del sistema de numerus clausus que amplía y, a la vez, limita esta vía de imputación en el Código Penal español (CP), sino de analizar la imprudencia como aquella cualidad de acciones que pueden asumirse dentro de las empresas. En otras palabras, sostengo que la infracción de los deberes objetivos de cuidado debería entenderse siempre como algo común respecto a la clase de infracciones susceptibles de realizarse al interior de la empresa; lo contrario, a mi juicio, implicaría mirar a estos entes como potenciales "fábricas de delitos", lo cual supondría un despropósito.

2. Cuando estudiamos la responsabilidad penal de las personas jurídicas ${ }^{1}$ encontramos que el tema central es la culpabilidad si dicho principio se mira, por lo menos, como mecanismo limitador de la intervención penal. ${ }^{2}$ Por ese motivo, entiendo que abarque la mayor parte de la discusión. ${ }^{3}$ La doctrina se ha cuestionado con intensidad algunos aspectos como la posibilidad de delinquir de una compañía; ${ }^{4}$ también, se ha preguntado cuál es la base para emitir un juicio de reproche a la empresa y por la viabilidad de aplicar una pena; en ese orden, ha intentado responder si la culpabilidad en sentido clásico puede encajar en las actividades empresariales. ${ }^{5}$ Como mencioné, al ser la culpabilidad el tema central en la responsabilidad penal para las personas jurídicas, el análisis de la imprudencia se desplaza a un punto de escaso interés. Por eso presentamos un análisis crítico de la imprudencia en materia de responsabilidad penal de la empresa.

1 Los artículos citados en esta contribución se refieren al Código Penal español, a no ser que se haga constar otra cosa.

2 Cfr. José Cerezo Mir, Derecho Penal. Parte General, Montevideo, Buenos Aires, Bdf, 2008, pp. 731-739; José Luís Manzanares Samaniego, Comentarios al Código Penal. Tras las Leyes Orgánicas 1/2015, de 30 de marzo, y 2/2015, de 30 de marzo, Madrid, La Ley, 2016, p. 171; Francisco Muñoz Conde y Mercedes García Arán, Derecho Penal. Parte general, 3 ed., Valencia, Tirant lo Blanch, 1998, pp. 391-398.

3 Cfr. Laufer/Strudler, "Corporate Intentionality, Desert, and Variants of Vicarius Liability", American Criminal Law Review 37 (2000), pp. 1256-1288.

4 Cfr. Jesús María Silva Sánchez, Fundamentos del derecho penal de la empresa, 2 ed., Montevideo, Buenos Aires, Bdf, 2016, pp. 274-276.

5 Cfr. Rafael Berruezo, Responsabilidad penal en la estructura de la empresa. Imputación jurídico-penal en base a roles, 2 ed., Montevideo, Buenos Aires, Bdf, 2018, pp. 19-29; Osvaldo Artaza Varela, La empresa como sujeto de imputación de responsabilidad penal. Fundamentos y límites, Madrid, Marcial Pons, 2013, pp. 45-50; Ana Isabel Pérez Machío, La responsabilidad penal de las personas jurídicas en el Código penal español. A propósito de los programas de cumplimiento normativo como instrumentos idóneos para un sistema de justicia penal preventiva, Granada, Comares, 2017, pp. 64-80. 
3. La Ley Orgánica (LO) 5/2010 modificó significativamente el sistema de responsabilidad penal en España. Se trata de una de las reformas más importantes que afectaron el CP. ${ }^{6}$ Tal es así que mediante esta reforma desaparece el denominado principio societas delinquere potest. ${ }^{7}$ Esa decisión, como habría de esperarse, significó un cambio notable en el sistema de atribución de responsabilidad penal, lo que ocasionó un sugestivo número de críticas por parte de la doctrina, incluso, antes de que dicha reforma entrara en vigor. ${ }^{8}$ En ese sentido, podemos afirmar que se trata de una decisión, cuanto menos, controvertida. Vamos a los ejemplos: el CP menciona la necesidad de adoptar modelos de organización y gestión que incluyan medidas de vigilancia y control idóneas para prevenir delitos. Se refiere a una de las causales de extinción de la responsabilidad penal, artículo 31 bis. ${ }^{9}$ A nuestro modo de ver, tanto las expresiones utilizadas en dicha causal como su contenido resultan imprecisas. ${ }^{10}$ Pero no solo le podemos criticar al legislador la utilización de expresiones ambiguas a la hora de fijar una de las causales de extinción de la responsabilidad penal, un asunto que repercute significativamente en el sistema de responsabilidad adoptado para las empresas. ${ }^{11}$ También, es objeto de crítica el catálogo de delitos por los cuales se puede declarar la responsabilidad penal. ${ }^{12}$ Me refiero, por una parte, a los delitos que no están presentes en ese cuadro; por otra, a la forma de imputación subjetiva que no se prevé para algunos de ellos. ${ }^{13}$ No convertiré este trabajo en un análisis de los delitos ausentes en el catálogo, ni en las conductas por

Cfr. Jesús María Silva Sánchez, “Introducción”, en Jesús María Silva Sánchez (dir.), El nuevo Código Penal. Comentarios a la reforma, Madrid, La Ley, 2012, pp. 33-42.

7 Cfr. Santiago Mir Puig, Derecho Penal. Parte general, 9 ed. Barcelona, Reppertor, 2011, p. 200; Manzanares Samaniego, Comentarios al Código Penal, op. cit., p. 1171.

8 Sobre la discusión con anterioridad al ante proyecto de forma del año 2008, véase Silvina Bacigalupo Saguesse, La responsabilidad penal de las personas jurídicas, Barcelona, Bosch, 1998, passim; Bernardo Feijoo Sánchez, Sanciones para empresas por delitos contra el medio ambiente, Madrid, Civitas, 2002, passim; Carlos Gómez-Jara Díez, La culpabilidad penal de la empresa, Madrid, Marcial Pons, 2005, passim; Carlos Gómez-Jara Díez, Fundamentos modernos de la responsabilidad penal de las personas jurídicas, Montevideo, Buenos Aires, Bdf, 2010, passim; Adán Nieto Martín, La responsabilidad penal de las personas jurídicas: un modelo legislativo, Madrid, Iustel, 2008, passim; Miguel Zugaldía Espinar, Responsabilidad penal de empresas, fundaciones y asociaciones: presupuestos sustantivos y procesales, Valencia, Tirant lo Blanch, 2008.

Desde la entrada en vigor de LO 5/2010 en España y hasta nuestros días, la bibliografía es abundante; por ese motivo, sugiero revisar las obras citadas en el siguiente manual: Adán Nieto Martín (dir.), Manual de cumplimiento penal en la empresa, Valencia, Tirant lo Blanch, 2015, passim.

9 Cfr. Silva Sánchez, Fundamentos del Derecho penal de la Empresa, op. cit., p. 275.

10 También da cuenta de ello, Adán Nieto Martín, "Cumplimiento normativo", en Nieto Martín (dir.), Manual de cumplimiento penal en la empresa, op. cit., pp. 25-27, entre otros lugares.

11 Sobre la doble vía para imputar responsabilidad penal a las personas jurídicas, véase, Bernardo del Rosal Blasco, Manual de responsabilidad penal y defensa penal corporativas, Madrid, La Ley, 2018, pp. 91-113; Jesús María Silva Sánchez, "La responsabilidad penal de las personas jurídicas en Derecho español”, en Jesús María Silva Sánchez (dir.), Criminalidad de empresa y Compliance. Prevención y reacciones corporativas, Barcelona, Atelier, 2013, pp. 21-34; Alicia Gil Gil, et al., Sistema de responsabilidad penal, Madrid, Dikinson, 2017, pp. 128-129.

12 A este respecto, son varias las expresiones que pueden ser criticadas con facilidad, por ejemplo, cuando el artículo 31 bis. 1 , inciso $1^{\circ}$ del CP se refiere a "los delitos cometidos en nombre o por cuenta de las mismas, y en su provecho, por sus representantes legales y administradores de hecho o de derecho". El término delitos cometidos es tan extenso que puede abarcar tanto las acciones realizadas como las intentadas; también abarca, a mi juicio, las conductas relacionadas con los tipos de autoría y participación. Para una crítica respecto al catálogo de delitos, véase Santiago Mir Puig, Derecho Penal. Parte general, 10 ed., Barcelona, Reppertor, 2015, pp. 844 y ss.

13 Cfr. Joan Baucells Lladós, Nuevas perspectivas de la política criminal europea en materia ambiental, Barcelona, Atelier, 2007, pp. 153-154. 
las cuales no se prevé la responsabilidad por imprudencia, a pesar de que una revisión de esa índole nos sirva para entender si existe o no un interés particular por parte del legislador de cara a la protección de ciertos bienes jurídicos, y, además, para determinar si el legislador ha tomado en serio este asunto en determinados sectores empresariales. Pues bien, una vez más, el objeto de esta investigación es argumentar por qué se castigan de manera imprudente las acciones cometidas en el marco de las actividades empresariales. ${ }^{14}$

En lo que sigue de mi exposición, mostraré un análisis sucinto de los delitos previstos por el legislador en este ámbito, concretamente, revisaré el bien jurídico protegido, la gravedad de la conducta y la clase de delito; de ese modo podré responder a la pregunta que engloba este trabajo; finalmente, presentaré la conclusión.

\section{Breve análisis de los delitos previstos por el legislador: criterios de clasificación}

1. Los delitos por los que pueden responder penalmente las empresas, en la actualidad, superan el número de veinte conductas. ${ }^{15}$ En esta sección mostraremos que existe protección para bienes jurídicos variados, es decir, tanto para bienes jurídicos individuales como colectivos; para la protección del medio ambiente y para el patrimonio económico; también para distintas clases de delitos, esto es, tanto para tipos de resultado como para delitos de mera actividad. Como dijimos, estamos ante a un grupo de infracciones diversas respecto a la forma en que pueden gestarse y materializarse conductas delictivas dentro de una empresa. ${ }^{16}$

Mostramos, a continuación, tres criterios de clasificación con miras a demostrar si existe o no un interés específico del legislador para un determinado grupo de bienes jurídicos, es decir, si se focaliza o no un área concreta en el ámbito empresarial ${ }^{17}$ (vid. 2.3).

Cfr. Günther Jakobs, Strafrecht. Allgemeiner Teil, Berlín, Nueva York, 1991, 8/5.

15 Ese conjunto de delitos son los siguientes: tráfico ilegal de órganos (art. 156 bis); trata de seres humanos (art. 177 bis); delitos relativos a la prostitución y corrupción de menores (art. 189 bis); delitos contra la intimidad y allanamiento informático (art. 197); estafas y fraudes (art. 251 bis); insolvencias punibles (art. 261 bis); daños informáticos (art. 264); delitos contra la propiedad intelectual e industrial, el mercado y los consumidores (art. 288); blanqueo de capitales (art. 302); financiación ilegal de partidos políticos (art. 304 bis); delitos contra la Hacienda Pública y la Seguridad Social (art. 310 bis); delitos contra los derechos de los ciudadanos extranjeros (art. 318 bis); delito de construcción, edificación o urbanización ilegal (art. 319); delitos contra el medio ambiente (arts. 327 y 328); delitos relativos a la energía nuclear y a las radiaciones ionizantes (art. 343); delitos de riesgo provocado por explosivos (art. 348); delitos contra la salud pública (art. 366 y 369 bis), falsedad en medios de pago (art. 399 bis), cohecho activo (art. 427.2); tráfico de influencias (art. 430); delitos de incitación al odio y a la discriminación (art. 510 bis); organizaciones o grupos criminales (art. 570 quáter); financiación del terrorismo (art. 576 bis) y contrabando (art. 2.6 LO 12/95 Modificada LO 6/2011).

16 Cfr. Del Rosal Blasco, Manual de responsabilidad penal y defensa penal corporativas, op. cit., pp. 56-60.

17 La clasificación de estos preceptos no se agota con los tres criterios que propongo. Es posible organizar dichas figuras a partir de otra perspectiva. Por ejemplo, seleccionando la mayor clase de delitos cometidos al interior 


\subsection{Por el bien jurídico}

1. Este primer criterio nos permitirá establecer la clase de "bienes jurídicos que pueden lesionarse mediante una persona jurídica", también servirá para determinar qué bienes jurídicos merecen mayor prevención en el ámbito de la empresa. Al aplicar esta línea de agrupación podemos analizar y estudiar cuáles son los riesgos penales que pueden gestarse al interior de una compañía, cuáles de estos pueden cometerse de manera imprudente y cuáles podrían estar más cercanos al dolo eventual que a la imprudencia, todo esto, teniendo presente el área de producción de cada compañía. ${ }^{18}$ Se trata de un análisis que dependerá, obviamente, de la clase de actividad que desarrollen las empresas.

De modo muy general las agrupamos de la siguiente manera.

i) Patrimonio económico y propiedad:

- Estafas y fraudes (art. 251 bis), patrimonio económico.

- Daños informáticos (art. 264), patrimonio ajeno y su integridad.

- Delitos contra la propiedad intelectual e industrial, el mercado y los consumidores (art. 288), propiedad y el derecho de los consumidores.

ii) Administración pública:

- Delitos contra la hacienda pública y la seguridad social (art. 310 bis), interés patrimonial de la Hacienda y la capacidad prestacional del sistema de protección social del Estado.

- Delitos contra los derechos de los ciudadanos extranjeros (art. 318 bis), control de los flujos migratorios por parte del Estado.

- Cohecho activo (art. 427.2), normal funcionamiento de la administración pública.

- Tráfico de influencias (art. 430), buen funcionamiento de la administración pública.

iii) Salud pública:

- Tráfico ilegal de órganos (art. 156 bis), correcto funcionamiento del sistema de trasplantes, salud individual, salud pública.

de las empresas; optando también por una selección de delitos menormente cometidos. Igualmente, podemos agruparlos por delitos que requieren una específica cualidad del sujeto activo. Ahora bien, en cuanto a los aspectos de política legislativa, sabemos que la técnica empleada para la elaboración de estos tipos no es igual, todo lo contrario, va cambiando o depende del aspecto de la conducta que se quiera resaltar, focalizarse en determinadas circunstancias o simplemente suprimirlas; de ahí deriva también la posibilidad de su clasificación.

18 Stefano Canestrari, Dolo eventuale e colpa cosciente. Ai confini tra dolo e colpa nella struttura delle tipologie delittuose, Milán, Giuffrè, 1999, pp. 292-294. 
- Delitos de riesgo provocado por explosivos (art. 348), salud pública, vida e integridad física de las personas.

- Delitos contra la salud pública (arts. 366 y 369 bis), conjunto de medios que garanticen la salud de los habitantes del Estado.

iv) Libertad:

- Trata de seres humanos (art. 177 bis), libertad personal.

- Delitos relativos a la prostitución y a la explotación sexual y corrupción de menores (art. 189 bis), libertad sexual.

- Descubrimiento y revelación de secretos (arts. 197, 197 bis y 197 ter), intimidad personal.

v) Medio ambiente:

- Delitos contra el medio ambiente (arts. 327 y 328), delitos relativos a la energía nuclear y a las radiaciones ionizantes (art. 343), sistema medioambiental.

vi) Seguridad del Estado, orden público y sistema democrático:

- Financiación ilegal de partidos políticos (art. 304 bis), correcto funcionamiento del sistema democrático de partidos.

- Delitos de incitación al odio y a la discriminación (art. 510 bis), orden público.

- Organizaciones o grupos criminales (art. 570 quáter), seguridad general de los ciudadanos.

- Financiación del terrorismo (art. 576), estabilidad y seguridad jurídica del Estado.

vii) Sistema económico nacional, derecho de crédito y cumplimento de normativa de contracción:

- Insolvencias punibles (art. 261 bis), derecho de crédito de los acreedores ante las conductas falsarias del sujeto que pretende engañar a los organismos determinados en el proceso concursal.

- Blanqueo de capitales (art. 301), sistema económico.

- Delito de construcción, edificación o urbanización ilegal (art. 319), cumplimiento de la normativa administrativa sobre construcción del territorio.

- Falsedad en medios de pago (art. 399 bis), autenticidad de los medios de pago en el sistema económico.

- Contrabando (art. 2.6 de la LO 12/95, modificada por la LO 6/2011), interés recaudatorio del Estado mediante el sistema arancelario. 
2. De esta agrupación podemos ver como este, por así llamarle, método de prevención, se extiende a bienes jurídicos donde el propio Estado es el titular directo; piénsese, por ejemplo, en la administración pública o en el sistema democrático. No solo se centra en el patrimonio económico y en bienes jurídicos afines a la dinámica societaria. Ahora bien, si se analiza con detenimiento la clasificación de los preceptos, encontraremos no pocos delitos que pueden ser castigados a título de imprudencia en el CP; además, aparecen algunos donde no está prevista esa modalidad, pero que perfectamente podrían "facturarse" por esa vía. ${ }^{19}$

\subsection{Por la gravedad de la conducta}

1. Los preceptos pueden agruparse también por la gravedad de la conducta ejecutada al interior de la empresa, aquí nos centraremos en el grupo de acciones imprudentes. Si acudimos a este criterio podemos establecer cuál de las conductas que se castigan por imprudencia presenta mayor necesidad de atención en el análisis de riesgos. En ese orden, convendría examinar en qué empresas se pueden gestar (o cometer) infracciones penales que afecten en mayor medida la reputación de la compañía. Esto resultaría de utilidad para la mejoría de medidas preventivas..$^{20} \mathrm{~A}$ este respecto, podemos señalar, cuanto menos, los siguientes delitos que se castigan a título de imprudencia en el marco empresarial: blanqueo de capitales (art. 301), riesgos provocados por explosivos (art. 347), financiación del terrorismo (art. 576.4), contrabando (por mandato del art. 2.6 de la LO 12/95, modificada por la LO 6/2011).

2. Del primer supuesto, blanqueo de capitales, podemos señalar, resumidamente, que se trata de una conducta que pretende cubrir con apariencia de legalidad los activos o bienes cuyo origen es ilícito. En esa línea, uno de los intereses objeto de protección es el orden socioeconómico. ${ }^{21}$ Puedo afirmar que el aspecto más controvertido es, sin temor a equivocarme, la

19 Aquí, desde mi punto de vista, resultan interesantes los motivos ya expuestos por la doctrina hispana. En concreto, puede consultarse una propuesta respecto al modo en que debe atenderse una acción para decir si forma o no parte del riesgo permitido o de un riesgo desaprobado (Yesid Reyes Alvarado, Imputación objetiva, 2 ed., Bogotá, Temis, pp. 73-78).

20 Cfr. Jesús María Silva Sánchez, Fundamentos del Derecho penal de la Empresa, op. cit., pp. 242-245; Beatriz Saura Alberdi, "Diseño e implementación del plan de prevención de delitos en la empresa", en Agustín Jesús PérezCruz Martín (dir.), Proceso penal y responsabilidad penal de personas jurídicas, Cizur Menor (Navarra), Aranzadi, 2017, pp. 295-298. Pensemos en el delito de financiación del terrorismo (art. 576) o en los delitos relativos a la prostitución y corrupción de menores (art. 189 bis). Si se da lugar a la imaginación o a la suposición, entiendo que ambas conductas no solo pueden gestarse al interior de una empresa, sino que son acciones que repercuten en mayor medida tanto en la sociedad como en la imagen de la empresa; en ese orden, se recomiendan mecanismos de prevención más rígidos.

$21 \mathrm{Al}$ analizar este delito, encontramos no pocas contradicciones. La doctrina científica parece estar cada vez más dividida respecto a la determinación del bien jurídico. Sobre esa discusión puede verse, entre otros autores, la opinión de María Dolores Serrano Tárraga, en Alfonso Serrano Gómez, et al., Curso de derecho penal. Parte especial, 4 ed., Madrid, Dykinson, 2017, pp. 438-439. 
inclusión del delito de blanqueo en la modalidad culposa. Me serviré de dos argumentos: el primero, porque contrasta con las previsiones contenidas en la Convención de Viena; el segundo, puesto que resulta difícilmente compatible con la materialización de la expresión blanquear, dado que dicha voz engloba una connotación eminentemente dolosa. Pues bien, la pena prevista para esta modalidad, en concordancia con el artículo 302.2 b) del $\mathrm{CP}$, corresponde a una multa de seis meses a dos años.

3. Respecto al segundo supuesto, riesgos provocados por explosivos, encontramos que su tipificación se fundamenta en la elevada peligrosidad que la conducta despliega ya de por sí para los bienes jurídicos protegido, esto es, la vida y la integridad de las personas. Se trata de un delito de resultado de peligro, ${ }^{22}$ y la inclusión de la modalidad imprudente no solo es factible, sino razonable, ${ }^{23}$ piénsese, por ejemplo, en el sujeto que, imprudentemente, pone en contacto con gasolina una colilla encendida de cigarro; o quien en el intento por suicidarse abre una pimpina de gas y provoca una explosión..$^{24}$ Respecto a la sanción, se trata de una pena de multa de uno a tres años por mandato del artículo 348.3 del CP.

4. Del tercer supuesto, delito de financiación del terrorismo, cabe señalar que está prevista su forma imprudente, pero de corte grave. Su realización es ampliamente discutible, pero su inclusión obedece a compromisos internacionales que sugieren garantizar de todas las formas posibles la evitación de acciones terroristas. El precepto contenido en el artículo 576.4 lo convierte en un delito especial, pues se refiere a sujetos que se encuentren específicamente obligados, por la ley, a colaborar con las autoridades en la prevención de actividades de financiación del terrorismo. Por mandato del artículo 2.1 de la Ley de Prevención de Blanqueo de Capitales y Prevención de la Financiación de Terrorismo, se le podría atribuir responsabilidad penal a un sugestivo número de empresas. ${ }^{25}$ Algunos autores, al comentar dicha conducta, sostienen que se trata del único delito terrorista que puede adjudicársele a una persona jurídica. ${ }^{26}$ En otro orden de asuntos, de conformidad con el artículo 576.5, corresponde aplicar una pena de multa de uno a tres años.

5. Finalmente, el delito de contrabando. Sobre este particular, el artículo 2.6 de la LO 6/2011 describe la tipificación de la conducta, y prevé para esta la

22 Cfr. Diego Manuel Luzón Peña, Lecciones de derecho penal. Parte general, 3 ed., Valencia, Tirant Lo Blanch, 2016, p. 161.

23 Sostiene otra opinión, Javier Sánchez-Junco Mans, en Cándido Conde-Pumpido Ferreiro (dir.), Código penal comentado, 3 ed., tomo I, Barcelona, Bosch, 2012, p. 1240.

24 Abundan ejemplos de esta clase en la jurisprudencia española, pongo por caso, SAP de Canarias, Sec. Tercera. 74/2009, 17 de marzo.

23625 Sin ir más lejos: empresas de servicios de inversión, entidades de crédito, entidades aseguradoras, entidades gestoras de fondos de pensiones, los casinos, los profesionales que comercialicen con joyas, entre otras.

26 En concreto, Carlos Vázquez González, en Serrrano Gómez, et al., Curso de derecho penal. Parte especial, op. cit., p. 891 . 
modalidad culposa. ${ }^{27}$ Se trata de un tipo mixto alternativo, y, además, de carácter pluriofensivo. ${ }^{28} \mathrm{El}$ bien jurídico protegido es, de manera generalizada, el interés recaudatorio del Estado a través del sistema arancelario; la tipificación de la contacta tiende, a su vez, a evitar un conjunto de acciones o actividades delictivas propias de la dinámica del contrabando: hurto, robo, extorsiones, amenazas; sin embargo, estas últimas conductas resultan incompatibles con el tipo imprudente. Si esto es así, debemos cuestionarnos la inclusión de la imprudencia para el delito de contrabando, esto es, determinar cuál es el motivo o los motivos que impulsan al legislador a tomar estas decisiones, no solo para esta última conducta, sino para las aquí comentadas. Ahora bien, respecto a la sanción, corresponde a una multa proporcional del duplo al cuádruplo del valor de los bienes, mercancías, géneros o efectos objeto del contrabando. Conjuntamente, se prevé la prohibición de obtener subvenciones y ayudas públicas para contratar con las administraciones públicas y para gozar de beneficios e incentivos fiscales o de la seguridad social por un plazo de entre uno y tres años.

6. Llegados a este punto podemos sostener que la inclusión del elemento subjetivo imprudente engloba un criterio eminentemente preventivo por parte del legislador español. Pasaré a explicarlo en lo que resta de esta sección. De las cuatro conductas analizadas, solo en una de ellas ("riesgos provocados por explosivos") resulta evidente la posibilidad de ser ejecutada de forma imprudente, dado que el resto de las acciones, como se mostró en el análisis, son bastante cuestionables respecto a su posible realización culposa. La financiación del terrorismo, el blanqueo de capitales, así como el delito de contrabando son tipos penales cuyos verbos rectores engloban un componente de fuerza o de engaño, esto es, de ataques o formas directas a intereses jurídicamente protegidos. Ahora bien, ¿qué sentido tienen estas consideraciones? Desde mi perspectiva, mucho. Y lo tienen porque lo mencionado recientemente de los tres últimos tipos puede afirmarse a su vez para el resto de delitos que se contienen en el cuadro (vid. 2.1). Y con esto amplificamos nuestro punto de examen. Si la mayoría de acciones previstas son dolosas y aquellas que prevén la modalidad culposa son de difícil o discutible materialización por esa forma de imputación subjetiva, es porque la medida se enmarca en criterios de estricta prevención. Se trata, entonces, de blindar a cualquier precio todos los supuestos posibles o hipotéticamente probables. De ese modo, se podría mirar a la empresa como un ente potencialmente delictivo. Esto, a mi juicio, engloba una medida de prevención que desborda los límites de la proporcionalidad, lo que denota falta de seriedad, por lo que no podría ser catalogada como una decisión política.

27 Jesús María Silva Sánchez, “Evolución de la posición de deber del Consejo de Administración. Una observación desde la cultura del Compliance", en Ramón Ragués i Vallès y Ricardo Robles Planas (dirs.), Delito y empresa. Estudios sobre la teoría del delito aplicada al derecho penal económico-empresarial, Barcelona, Atelier, 2018, p. 51. 


\subsection{Por la clase de delitos}

1. La tercera forma de agrupar estos preceptos es por la clase de delitos; esto es, por delitos de resultado, de peligro o de preparación. A mi modo de ver, quien tenga en cuenta este criterio podrá identificar y, a su vez, graduar los niveles de prevención que requieren las conductas que se procuren prevenir; esto, obviamente, repercute en los estándares que han de tener presentes los programas de cumplimiento en las empresas. Si de lo que se trata es de adoptar patrones para la prevención delictiva, los tipos de preparación, por citar un ejemplo, llevan consigo la necesidad de readaptar mejores mecanismos preventivos, puesto que representan un adelantamiento de las barreras de punición (algo similar habrá de asumirse para los delitos de peligro ${ }^{29}$ ).

2. Por lo anterior, estimo necesario focalizar la elaboración de programas de cumplimento normativo no solamente para delitos de resultado como la estafa (art. 251) o el delito de daños informáticos (art. 264), sino también para otras conductas que implican mayor complejidad en materia de prevención delictiva, pues en ese catálogo se contienen no pocos delitos de peligro concreto como el de explotación de instalaciones donde se realicen actividades peligrosas o las que almacenen sustancias que causen o puedan causar daños a la calidad del aire, el suelo, los animales o las plantas, así como la muerte o lesión grave a las personas $\left(326\right.$ bis $\left.^{30}\right)$. Además, de peligro presunto, como lo es el delito de transporte de residuos (art. 326. $2^{31}$ ); el delito de peligro abstracto (mera actividad o consumación anticipada), así como el delito de elaboración, tráfico, ejecución o favorecimiento ilegal del consumo de drogas (art. 368 ${ }^{32}$ ). Se contienen, además, delitos de preparación como la falsificación de moneda (art. 386.533) o el delito de publicidad engañosa (art. $282^{34}$ ). También aparecen tipos de medio a fin como el delito de falsedad documental ampliado $\left(\operatorname{art} .362\right.$ ter $\left.^{35}\right)$. Y, conjuntamente, delitos especiales, como financiación del terrorismo (art. 576.74).

3. La inmensa mayoría de estas conductas presenta algo en común: el distanciamiento de la producción del resultado indeseado. Podemos afirmar, en primer lugar, que no existe, por así decirlo, un bien jurídico al que el legislador le haya brindado una atención especial, dado que las acciones descritas en el catálogo no nos revelan una diferencia considerable

29 Véase Alain Casanovas Ysla, Compliance penal normalizado. El estándar UNE 19601, Cizur Menor (Navarra), Aranzadi, 2017, pp. 110-120.

30 Cfr. Manzanares Samaniego, Comentarios al Código Penal, op. cit., pp. 1123-1124.

31 Cfr. A. Vercher Noguera, en Antonio del Moral García (dir.), Código Penal. Comentarios y jurisprudencia, tomo II, Granada, Comares, 2018, pp. 2064.

32 Cfr. Serrano Gómez y Serrano Maíllo, en Curso de derecho penal. Parte especial, op. cit., pp. 601-616. 2018, pp. 2168-2169. 
en términos cuantitativos, me refiero a los derechos protegidos o bienes jurídicos relacionados en esos tipos penales. En segundo lugar, tampoco existe una explicación respecto de los criterios utilizados por el legislador para seleccionar las conductas por las cuales a una persona jurídica se le hace responsable; cuanto menos, esa referencia no aparece desarrollada ni en el texto de la ley ni en la exposición de motivos. En ese orden de asuntos, se evade una explicación de por qué determinados delitos están y otros no, o por qué para algunos se prevé la imprudencia y para otros se reserva esa modalidad.

De cara a los sistemas de prevención, parece lógico que la posición de garantía de los administradores, tanto la orientada a evitar resultados lesivos para la empresa como la tendiente a impedir resultados que se produzcan sobre las personas externas mediante acciones ejecutadas por miembros de las compañías parece verse afectada con los delitos de preparación o de peligro. Por esto, asumimos que implantar programas de cumplimiento que incluyan los aspectos comentados dotará de eficacia dicha medida. La pregunta es, entonces, si vale la pena la inclusión de un programa de cumplimento tendiente a evitar esta clase de delitos. ${ }^{36}$ La respuesta ha de ser siempre sí, pues la existencia de estos programas neutraliza imputaciones de imprudencia dirigidas contra directivos de las compañías. Para recapitular, no existe un conjunto de bienes jurídicos que sean de especial interés para el legislador en esta materia preventiva, es decir, la medida no resulta excluyente. Por otro lado, la mayoría de conductas relacionadas engloba un componente doloso, lo que deja la imprudencia en un mínimo posible. Además, como señalamos, estas últimas acciones, las imprudentes, son bastante cuestionables respecto a su factible ejecución pese a estar prevista dicha modalidad (vid. 2.6).

Agotada tanto la parte descriptiva como la crítica de este trabajo, en lo que resta mostraré cual es la razón o las razones por las cuales castigamos delitos imprudentes cometidos en el marco de las actividades empresariales, $y$, finalmente, presentaré la conclusión.

\section{El castigo de acciones imprudentes al interior de la empresa}

1. Las empresas, normalmente, no centran su dinámica societaria en la delincuencia, es decir, no se dedican a la maquinación, preparación y posterior

$36 \quad$ Cfr. Ulrich Sieber, “Programas de compliance en el derecho penal de la empresa. Una nueva concepción para controlar la criminalidad económica", en Luis Alberto Arroyo Zapatero y Adán Nieto Martín (dirs.), El derecho penal económico en la era del compliance, Valencia, Tirant lo Blanch, 2013, pp. 98-99: “La auto regulación de la empresa puede constituir un planteamiento mucho más efectivo que la determinación estatal de preceptos, que en parte no se adaptarán a cada empresa en concreto. El hecho de delegar a las empresas internacionales determinadas formas de selfpolicing no implica una laissez-faire, sino que en muchos casos es la única forma de recuperar una parte del control estatal bajo la forma de autorregulación regulada o de la rule at a distance". 
comisión de delitos, ${ }^{37}$ sino que focalizan sus actividades en la prestación de servicios, a no ser que se trate de una organización criminal encubierta. Analizar las conductas imprudentes como algo propio de las actividades empresariales cobra sentido, ya que la ejecución de acciones imprudentes se incrementa en razón de la imparable industrialización, así como de los peligros que asumimos ordinariamente, y en este punto también se incluye el ámbito empresarial.

Existe una diferencia fundamental entre las conductas que se realizan dolosamente frente a aquellas que se producen de forma imprudente. Las primeras, por lo general, ${ }^{38}$ están supeditadas a un concreto proyecto delictivo que implica conocer, no solo la ilicitud de la conducta, ${ }^{39}$ sino el funcionamiento de la empresa, pues es necesario, por así decirlo, servirse de la estructura empresarial para delinquir. A mi juicio, existe una estructura medial claramente determinada en las acciones dolosas desarrolladas en el marco de las actividades empresarial, no así en las conductas imprudentes. Pensemos, por ejemplo, en el delito de estafa: una constructora inicia la venta de apartamentos de un edificio que se encuentra en planos, utilizando esa estructura para delinquir. También puede determinarse una estructura medial en el delito de tráfico de órganos; por ejemplo, una compañía de helados transporta en sus camiones de reparto órganos humanos y utiliza la estructura para facilitar la comisión de ese delito. Ambas estructuras obedecen a una planificación delictiva, impropia de lo que debería ser una empresa; de manera que, como se mencionó, en ambos ejemplos se desvirtúa la noción de empresa, estoy pensando en su función social.

2. Las acciones imprudentes, por el contrario, no están sujetas a un plan delictivo, ${ }^{40}$ estas surgen, por así decirlo, de los imprevistos de la vida ordinaria; por tanto, hablamos de la infracción de un deber objetivo de cuidado, de una falta de previsibilidad, advertibilidad, evitabilidad. Para esas expresiones (previsibilidad, advertibilidad...) no se deberían buscar significados específicos, puesto que la función del penalista consiste en emplearlas como criterios de imputación a fin de excluir los riesgos jurídicamente relevantes en la valoración de acciones imprudentes. ${ }^{41}$ Las infracciones imprudentes surgen mediante un descuido, en un instante; se producen sin querer, "cualquiera puede realizarlas". En el ámbito que ahora revisamos,

37 Cfr. Mir Puig, Derecho penal. Parte general, op. cit., p. 204.

38 A mi modo de ver, la excepción a esa regla puede aparecer en el denominado dolo eventual, donde el sujeto no desarrolla o planifica un proyecto delictivo específico, pero mediante su conocimiento asume, libremente, la responsabilidad del resultado lesivo que puede causar dentro del marco de actividades tanto lícitas (tráfico vial) como ilícitas (tráfico de precursores).

39 Cfr. Alfonso Reyes Echandía, Obras completas, vol. I, Bogotá, Temis, presentación de Yesid Reyes Alvarado, 1998, p. 646.

24040 Cfr. Harro Otto, Manual de derecho penal. Teoría general del derecho penal, 7 ed., Barcelona, Atelier, trad. de José Béguelin, 2017, pp. 293-296.

41 Cfr. Karl Binding, Die Normen und iher übertretung, vol. 4, 4 ed. Leipzig, 1919, reimpre., Aalen 1991, pp. 114, 118, 154, 155. 
las puede realizar desde un alto directivo de la empresa hasta el recepcionista del edificio. Como decíamos, dichas conductas no están proyectadas ni supeditadas a un plan (delictivo), sino que forman parte de los riesgos asumidos en las actividades comerciales. Sin embargo, a raíz de una acción imprudente se pueden generan resultados que muchas veces son irreversibles $^{42} \mathrm{o}$, sin serlo, desestabilizan el orden empresarial deseado, motivos que justifican la imposición de una sanción.

3. En las estructuras empresariales esto cobra sentido si se analizan con cierto detenimiento los aspectos relacionados con la estructura organizativa formal e informal (pautas de seguimiento positivas y pautas consuetudinarias internas) ${ }^{43}$ Ahora bien, si las personas jurídicas, como hemos reiterado, no enfocan sus esfuerzos en la comisión de acciones dolosas, sino que dentro de su accionar surgen infracciones de deber, faltas de previsibilidad, carencias de advertibilidad o evitabilidad, considero más que razonable la inclusión de esta forma de "imputación subjetiva".

Brindamos varias razones para atender la imprudencia en este ámbito, dado que dicha forma de culpabilidad está vinculada con los aspectos ordinarios de las empresas. No así la modalidad dolosa, la cual debe entenderse, en mi opinión, como un fracaso en las relaciones mercantiles. Si al interior de una empresa se comete una infracción dolosa, la compañía deberá asumir toda la carga jurídica y social que represente la infracción cometida, pues ha vulnerado el principio de confianza en las relaciones comerciales que implica un conjunto de intereses superiores. Esto se evidencia, al tomar su estructura jurídico-empresarial como medio delictivo, es decir, al utilizar a la empresa como plataforma criminal, un asunto, desde mi perspectiva, injustificable ${ }^{44}$ dentro de los postulados de un Estado social y democrático de derecho. ${ }^{45}$

42 Por ejemplo, un sujeto cruza la cebra cuando el semáforo está en verde para el peatón; este es atropellado mortalmente por el conductor de un vehículo que, "sin querer", al revisar un mensaje en el teléfono no logra frenar la máquina.

43 Como se sabe, en las empresas existen tanto normas de seguimiento positivizadas en reglamentos como las no escritas. Estas últimas - posiblemente- pueden llegar a contener mayor fuerza vinculante, puesto que son la esencia de la cultura organizacional de cada compañía. "Aquí siempre se han hecho las cosas de esta manera". La anterior expresión suele empleare en una determinada aérea de trabajo, alegando al modo de proceder o la forma de solucionar un asunto.

44 Sobre este particular, véase Gabriel Rodríguez-Ramos Ladaria, Código Penal concordado y comentado con jurisprudencia, 6 ed. Madrid, La Ley, 2017, p. 383, donde se señala expresamente que: "La sociedad meramente instrumental o de 'pantalla', creada exclusivamente para servir de instrumento en la comisión del delito por la persona física, ha de ser considerada al margen del régimen de responsabilidad del artículo 31 bis, por resultar insólito pretender realizar valoraciones de responsabilidad respecto de ella, dada la imposibilidad congénita de ponderar la existencia de mecanismos internos de control y, por ende, de cultura de respeto o de desafectación a la norma, respecto de quien nace exclusivamente con una finalidad delictiva que agota la propia razón de su existencia y que, por consiguiente, quizás hubiera merecido en su día directamente la disolución por vía del art. $129 \mathrm{CP}$, que contempla la aplicación de semejante 'consecuencia accesoria'".

45 La empresa, en un Estado social y democrático de derecho, también debe pretender valores como la libertad, la justicia, el pluralismo y la igualdad; porque utilizar una persona jurídica para delinquir no solo es contradictorio a estos valores, sino que quien se sirva de dicha plataforma deberá asumir toda la carga tanto reputacional como jurídica. 
4. La imprudencia puede aceptarse como un modo de castigo excepcional al que algunos denominan como imputación extraordinaria. ${ }^{46}$ Ahora bien, en el ámbito empresarial, el tipo imprudente debería entenderse como ese algo "asumible" o "posible" dentro de las reglas de la sana competencia, así como de las actividades mercantiles en las sociedades modernas. ${ }^{47} \mathrm{En}$ ese sentido, lo ideal debería ser, únicamente, el castigo de acciones imprudentes (pero no necesariamente mediante el sistema penal ${ }^{48}$ ). Y tampoco habrá de aceptarse la inclusión de esta modalidad solamente por aumentar los estándares preventivos pues, como se mencionó, esta clase de decisiones nos llevan a desbordar los límites de la proporcionalidad. Expresado de otra manera, la necesidad del fenómeno sociológico que representan esas conductas no debería impulsar al Estado a ensanchar las barreras de protección hasta el punto de emitir medidas irracionales.

En esa línea, la sanción de las acciones imprudentes cometidas dentro de las empresas se vería justificada por el reconocimiento de la imperfección de las compañías, pues, detrás de las personas juridicidad actúan, en definitiva, personas naturales. Los "errores de previsibilidad" en entornos complejos como el sector empresarial son casi insalvables, no así la planificación de conductas dolosas. ${ }^{49} \mathrm{~A}$ mi parecer, entran en juego motivos tanto de necesidad como de merecimiento de pena. Es necesario castigar pese a los esfuerzos por evitar defectos de organización, dado que pueden presentarse resultados de carácter irreversible; por tanto, las empresas se obligan a mejorar sus sistemas de organización. A mi juicio, la sanción impulsará a prevenir dichas conductas en el mismo o en diferentes sectores comerciales. Y, a su vez, de merecimiento; son merecedoras de castigo aquellas conductas que lesionan bienes jurídicos relevantes dentro del margen de las relaciones empresariales donde estas enfocan sus intereses mercantiles. Dicho esto, la sanción de las conductas imprudentes no debe asumirse exclusivamente como una decisión de política criminal de corte preventivo, ${ }^{50}$ sino como parte del precio que habrá de asumirse por los resultados inalienables que se suscitan al interior de la actividad comercial.

46 De otra opinión, Carlos Pérez del Valle, La imprudencia en el derecho penal. El tipo subjetivo del delito imprudente, Barcelona, Atelier, 2012, p. 148.

47 De opinión similar, confróntese la tesis sostenida por M. Köler, "El concepto de imputación", en Edgardo Donna (dir.), Problemas fundamentales de la imputación objetiva, tomo II, Buenos Aires, Rubizal-Culzoni Editores, 2015, p. 508, que al describir el pensamiento central de la imputación subjetiva, a partir de la visión de Aristóteles, señala que: "Solo la acción voluntaria merece elogio o repudio y pena, no aquella que sucede involuntariamente sin consentimiento del significado normativo concreto del obrar".

48 Afirmo que las sanciones no deben ser necesariamente penales, dado que no comparto que a las personas jurídicas se les haga penalmente responsables. No pretendo servirme de esta contribución para desarrollar mi objeción; sin embargo, pueden consultarse algunas buenas razones en: Santiago Mir Puig, Derecho penal. Parte general, op. cit., pp. 195-211.

49 Sobre este punto, ver Reyes Echandía, Obras completas, op. cit., pp. 642-643.

50 Me refiero, concretamente, a enmarcar esta disciplina en una variante de prevención general positiva. 


\section{Conclusión}

1. El modo de proceder del legislador al incluir la modalidad imprudente en esta materia resultaría acertado siempre que se atienda a la imprudencia como la forma de imputación subjetiva ideal para las empresas y no como un modo amplificador inspirado en parámetros estrictamente preventivos. En efecto, quedan algunos temas por resolver, sin ir más lejos: la inclusión de ciertos delitos y la exclusión de otros; el castigo de determinadas acciones y la complejidad o poca claridad sobre la inclusión de estas en materia de responsabilidad penal para las personas jurídicas. Estas cuestiones siguen siendo válidas en el debate académico puesto que, como se mencionó, ni el texto de la ley ni las exposiciones contienen explicación alguna. Conviene tener presente la cuestión de por qué castigamos acciones imprudentes en las actividades empresariales. Sancionar las acciones imprudentes realizadas en el marco de las actividades empresariales significa mirar a la empresa como un ente susceptible de errores, imperfecto, mejorable en su estructura, mutable; pero con vocación de servicio en el marco del Estado social y democrático de derecho. Lo ideal es que no fuera necesaria la responsabilidad penal para las empresas y que estas desarrollaran sus actividades, siempre, en el marco de la legalidad. Sostengo que las acciones imprudentes son las únicas que debemos tolerar respecto de la responsabilidad de las personas jurídicas; de ahí que el castigo de estas acciones sea moderado y se estime como "asumible" en el marco de las actividades empresariales.

2. Esta contribución corresponde a una tesis que debe adoptarse únicamente como un breve esbozo dentro del complejo mundo de las relaciones comerciales que abordan las empresas. La elaboración de toda esta noción (me refiero a los aspectos fundamentales de la dogmática de la imprudencia, así como a los detalles de la teoría de la peana involucrados en ella) implica un mayor espacio del que dispongo.

\section{Bibliografía}

Artaza Varela, Osvaldo, La empresa como sujeto de imputación de responsabilidad penal. Fundamentos y límites, Madrid, Marcial Pons, 2013.

Bacigalupo Saguesse, Silvina, La responsabilidad penal de las personas jurídicas, Barcelona, Bosch, 1998.

Baucells Lladós, Joan, Nuevas perspectivas de la política criminal europea en materia ambiental, Barcelona, Atelier, 2007.

Berruezo, Rafael, Responsabilidad penal en la estructura de la empresa. Imputación jurídico-penal en base a roles, 2 ed., Montevideo, Buenos Aires, Bdf, 2018. 
Binding, Karl, Die Normen und iher übertretung, vol. 4, 4 ed., Leipzig, 1919, reimpre., Aalen, 1991.

Canestrari, Stefano, Dolo eventuale e colpa cosciente. Ai confini tra dolo e colpa nella struttura delle tipologie delittuose, Milán, Giuffrè, 1999.

Casanovas Ysla, Alain, Compliance penal normalizado. El estándar UNE 19601, Cizur Menor (Navarra), Aranzadi, 2017.

Cerezo Mir, José, Derecho penal. Parte general, Montevideo, Buenos Aires, Bdf, 2008.

Del Rosal Blasco, Bernardo, Manual de responsabilidad penal y defensa penal corporativas, Madrid, La Ley, 2018.

Dopico Gómez-Aller, Jacobo, en Íñigo Ortiz de Urbina (coord.), Memento Experto Reforma Penal, Madrid, BCA, 2010, 1/140.

Feijoo Sánchez, Bernardo, Sanciones para empresas por delitos contra el medio ambiente, Madrid, Civitas, 2002.

Gil Gil, Alicia et al., Sistema de Responsabilidad Penal, Madrid, Dykinson, 2017.

Gómez-Jara Díez, Carlos, La culpabilidad penal de la empresa, Madrid, Marcial Pons, 2005.

Gómez-Jara Díez, Carlos, Fundamentos modernos de la responsabilidad penal de las personas jurídicas, Montevideo, Buenos Aires, Bdf, 2010.

Jakobs, Günther, Strafrecht. Allgemeiner Teil, Berlín, Nueva York, 1991.

Manzanares Samaniego, José Luis, Comentarios al Código Penal. Tras las Leyes Orgánicas 1/2015, de 30 de marzo, y 2/2015, de 30 de marzo, Madrid, La Ley, 2016.

Mestre Delgado, Esteban y Carmen Lamarca Pérez (coord.), Delitos. La parte especial del derecho penal, 3 ed., Madrid, Dykinson, 2017.

Mir Puig, Santiago, Derecho Penal. Parte general, 9 ed., Barcelona, Reppertor, 2011.

Muñoz Conde, Francisco y Mercedes García Arán, Derecho penal. Parte general, 3 ed., Valencia, Tirant lo Blanch, 1998.

Muñoz Conde, Francisco y Mercedes García Arán, Derecho penal. Parte general, 9 ed., Valencia, Tirant lo Blanch, 2015.

Nieto Martín, Adán, La responsabilidad penal de las personas jurídicas: un modelo legislativo, Madrid, Iustel, 2008.

Nieto Martín, Adán, “Cumplimiento normativo", en Adán Nieto Martín (dir.), Manual de cumplimiento penal en la empresa, Valencia, Tirant lo Blanch, 2015.

Otto, Harro, Manual de Derecho Penal. Teoría general del Derecho Penal, 7 ed., Barcelona, Atelier, trad. de José Béguelin, 2017. 
Perales Calleja, Juan, en Antonio del Moral García (dir.), Código Penal. Comentarios y jurisprudencia, tomo II, Granada, Comares, 2018.

Pérez del Valle, Carlos, La imprudencia en el derecho penal. El tipo subjetivo del delito imprudente, Barcelona, Atelier, 2012.

Pérez Machío, Ana Isabel, La responsabilidad penal de las personas jurídicas en el Código penal español. A propósito de los programas de cumplimiento normativo como instrumentos idóneos para un sistema de justicia penal preventiva, Granada, Comares, 2017.

Reyes Alvarado, Yesid, Imputación objetiva, 2 ed., Bogotá, Temis.

Reyes Echandía, Alfonso, Obras completas, vol. I, Bogotá, Temis, present. de Yesid Reyes Alvarado, 1998, p. 646.

Saura Alberdi, Beatriz, "Diseño e implementación del plan de prevención de delitos en la empresa", en Agustín Jesús Pérez-Cruz Martín (dir.), Proceso penal y responsabilidad penal de personas jurídicas, Cizur Menor (Navarra), Aranzadi, 2017.

Serrano Gómez, Alfonso y Alfonso Serrano Maíllo, Curso de derecho penal. Parte especial, 4 ed. Madrid, Dykinson, 2017.

Sieber, Ulrich, "Programas de compliance en el derecho penal de la empresa. Una nueva concepción para controlar la criminalidad económica", en Luis Alberto Arroyo Zapatero y Adán Nieto Martín (dirs.), El derecho penal económico en la era del compliance, Valencia, Tirant lo Blanch, 2013.

Silva Sánchez, Jesús María, “Introducción”, en Jesús María Silva Sánchez (dir.), El nuevo Código Penal. Comentarios a la reforma, Madrid, La Ley, 2012.

Silva Sánchez, Jesús María, “La responsabilidad penal de las personas jurídicas en Derecho español", en Jesús María Silva Sánchez (dir.), Criminalidad de empresa y Compliance. Prevención y reacciones corporativas, Barcelona, Atelier, 2013.

Silva Sánchez, Jesús María, Fundamentos del Derecho penal de la Empresa, 2 ed., Montevideo, Buenos Aires, Bdf, 2016.

Vercher Noguera, A., en Antonio del Moral García (dir.), Código Penal. Comentarios y jurisprudencia, tomo II, Granada, Comares, 2018.

Zugaldía Espinar, Miguel, Responsabilidad penal de empresas, fundaciones y asociaciones: presupuestos sustantivos y procesales, Valencia, Tirant lo Blanch, 2008. 